\title{
A STUDY TO EVALUATE THE ROLE OF DACRYOCYSTOGRAM IN PATIENTS WITH CHRONIC DACRYOCYSTITIS
}

\author{
Subbiah Vasan Chandrakumar1, Ponnusamy Thiyagarajan², Rangasamy Priyadharsini3, Anu Joseph4, \\ Anupriyadarshini Arumuga Nainar 5
}

\author{
${ }_{1}^{1}$ Associate Professor, Department of Ophthalmology, Madurai Medical College. \\ 2 Professor, Department of Ophthalmology, Madurai Medical College. \\ ${ }^{3}$ Senior Resident, Department of Ophthalmology, Madurai Medical College. \\ 4Junior Resident, Department of Ophthalmology, Madurai Medical College. \\ 5Junior Resident, Department of Ophthalmology, Madurai Medical College.
}

\begin{abstract}
BACKGROUND

Chronic dacryocystitis is one of the most common cause of epiphora due to insufficient drainage. Dacryocystogram by linear tomography with Omnipaque precisely helps us to determine the site of Nasolacrimal Duct (NLD) block. It helps us to arrive at the indications of surgery and also to plan the type of surgery that has to be performed.
\end{abstract}

\section{METHODS}

A total number of 40 patients who attended as outpatient and admitted in the wards of Department of Ophthalmology, Govt. Rajaji Hospital, Madurai, who satisfy the inclusion criteria were taken up for this prospective observational study. Dacryocystogram was performed after explaining the procedure to the patient and obtaining informed consent.

\section{RESULTS}

Incidence of chronic dacryocystitis is more common among females, the older females and younger males were commonly affected. The involvement of left side was more common than right side. NLD block 95\% was more common than canaliculi block. Incomplete block was seen in $25 \%$ patients. The morphology of nasolacrimal sac was normal in 12 patients, distended in 17 and fibrosed in 11 of them. Dacryocystogram delineate the altered tract (fistula) being external in 2 patients. Residual lacrimal sac following incomplete excision of sac was seen in one patient for whom DCT was performed earlier. Dacryolithiasis was also detected. Based on Dacryocystogram finding, Dacryocystectomy (DCT) was advised in maximum number of cases 55\% followed by Dacryocystorhinostomy (DCR) in $40 \%$ and excision of fistulous tract along with Dacryocystectomy was performed in $5 \%$ of them.

\section{CONCLUSIONS}

Outcome after surgery on follow-up with syringing showed no regurgitation of mucopurulent fluid in majority of cases (P value $<0.001$ and hence significant). It is evident from the findings derived from this study that Dacryocystogram is a safe investigating modality in the hands of skilled ophthalmologist and radiologist. It aids us to localise the level of block, analyse the changes in morphology of sac and lacrimal duct, at times the aetiological factor for epiphora can be diagnosed based on it enabling us to plan the treatment in a much better way, thereby better outcome following surgery can be achieved without recurrence.

\section{KEYWORDS}

Dacryocystitis, Lacrimal Fistula.

HOW TO CITE THIS ARTICLE: Chandrakumar SV, Thiyagarajan P, Priyadharsini R, et al. A study to evaluate the role of dacryocystogram in patients with chronic dacryocystitis. J. Evolution Med. Dent. Sci. 2016;5(75):5555-5557, D0I: $10.14260 /$ jemds/2016/1255

\section{INTRODUCTION}

Chronic dacryocystitis is one of the most common causes of epiphora due to insufficient drainage. The insufficient drainage is due to either congenital causes like punctal atresia, diverticulum or fistula from sac to nose or cheek, Nasolacrimal Duct Obstruction (NLD), agenesis or acquired causes ${ }^{1}$ like punctal stenosis due to age-related atrophic

Financial or Other, Competing Interest: None.

Submission 12-08-2016, Peer Review 07-09-2016,

Acceptance 12-09-2016, Published 17-09-2016.

Corresponding Author:

Dr. Subbiah Vasan Chandrakumar,

\#C3, Aastha Apartment,

Manimegalai Street,

Sathyasai Nagar, Madurai-625003,

Tamilnadu.

E-mail: eyedrck@gmail.com

DOI: $10.14260 /$ jemds/2016/1255

processes, chronic disease, dacryoliths, allergy, systemic chemotherapeutic agents, postherpetic infection (Herpes simplex, varicella zoster), bacterial infection (Actinomyces, Chlamydia), Wegener granulomatosis, sarcoidosis, hay fever, atopy, etc.

The other uncommon causes are intranasal processes, facial bone fractures, intrinsic tumour, compression or invasion and occlusion by adjacent tumour, a scaring process that may be surgical or non-surgical, foreign body and post irradiation. Dacryocystogram by linear tomography with Omnipaque precisely helps us to determine the site of NLD block, stenosis of the excretory duct provide appropriate details for evaluating the diagnosis of diverticula, fistula or filling defects caused by stones and tumours. It helps to arrive at the indications of surgery and also to plan the type of surgery that has to be performed. 


\section{Study Design}

A total number of 40 patients who attended as outpatient and admitted in the wards of Department of Ophthalmology, Govt. Rajaji Hospital, Madurai who satisfy the inclusion criteria were taken up for this prospective observational study.

\section{Inclusion Criteria}

Patients diagnosed with chronic dacryocystitis, recurrence of disease after DCT /DCR surgery and of age more than 12 years and less than 70 years.

\section{Exclusion Criteria}

Pregnant mothers, hypertensive with BP more than 140/90 mmHg, age less than 12 years and more than 70 years, immunocompromised patients, history of anaphylaxis, allergy to contrast drugs, patients not consenting for the study.

\section{METHODS}

Dacryocystogram is performed after explaining the procedure to the patient and obtaining informed consent. With patient in supine position, a drop of topical anaesthetic agent Proparacaine $0.5 \%$ was applied into the patient's conjunctiva of both the eyes. The inferior punctum was dilated with a Nettleship punctum dilator. Approximately, 1-2 $\mathrm{mL}$ of non-ionic water soluble contrast (Iohexol) was injected into lacrimal systems of both eyes without any spill over of dye. Skiagrams were then taken immediately following the injection in the postero-anterior view and then in the oblique view.

\section{Normal Dacryocystogram}

The dye reflux is minimal and there is no pooling of dye anywhere in the lacrimal passage and flows freely into the nasal cavity. The canaliculi are outlined joining the lateral wall of sac after uniting to form common canaliculi. The lacrimal sac has uniform "C" shape outline with no undulations or filling defects in it. There are mainly two constrictions, the valves of Krause being in the proximal third and the valve of Taillefer in the lower third. This is followed by the nasolacrimal duct, which opens into the nasal cavity.

The delayed films take later show either emptying or filling defects, which outline growth of mass or stones. Residual pooling 2 seen in delayed picture taken in the sitting posture also gives effect of gravity in draining.

\section{Abnormal Dacryocystogram}

The behaviour of dye that was injected into the catheter gives different interpretations. Failure of the injected dye to reach the nose indicates an anatomical obstruction in the NLD system and the site of obstruction is evident. A normal Dacryocystogram in the presence of epiphora indicates a mild incomplete anatomic block or physiologic dysfunction.

The diagnosis of functional nasolacrimal duct obstruction (FNLDO) $^{3}$ is made when there is poor emptying, such that residual contrast pooling is present in the lacrimal sac or nasolacrimal duct on the delayed radiograph. Dacryocystography is also helpful in the diagnosis of diverticula, fistulae and filling defects caused by stones or tumours. The presence of super numeric calculi is well counted and identified. Imaging of the canaliculi with dye, but failing to pass into the lacrimal sac or NLD implies obstruction at the level of common canaliculi.
Obstruction at level of the nasolacrimal sac and lacrimal duct junction usually results in a well dilated sac with no dye reaching the duct or nose (Fig. 1), even on delayed films. Obstruction involving the nasolacrimal duct orifice will show dilatation of the lacrimal sac with dye in the nasolacrimal duct, but not reaching the nose. Dacryocystogram is also then carefully evaluated to assess the grade of reflux from the upper canaliculi, the size of the lacrimal sac in $\mathrm{mm}$ and the nasolacrimal duct calibre in $\mathrm{mm}$ and comments made on the presence of any filling defects or diverticula. Finally, a subjective estimate is made for each abnormal Dacryocystogram to locate the area of chief "hold up" lies in the canalicular system at the lacrimal sac duct junction or within the NLD.

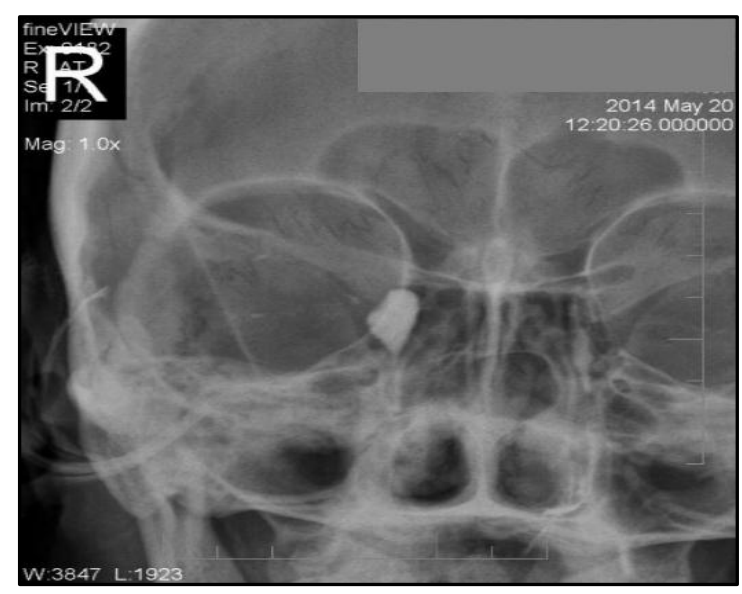

Fig. 1: Dacryocystogram done showing Pooling of Dye within the Distended Sac Demonstrating Obstruction at Sac Duct Junction

Dacryocystogram with digital subtraction radiography 4 can eliminate confusing bone shadows to identify the exact morphology of the sac outlined. Dacryocystogram following failed DCR surgery can help us to see pooling of dye in middle meatus and also stricture of ostium.

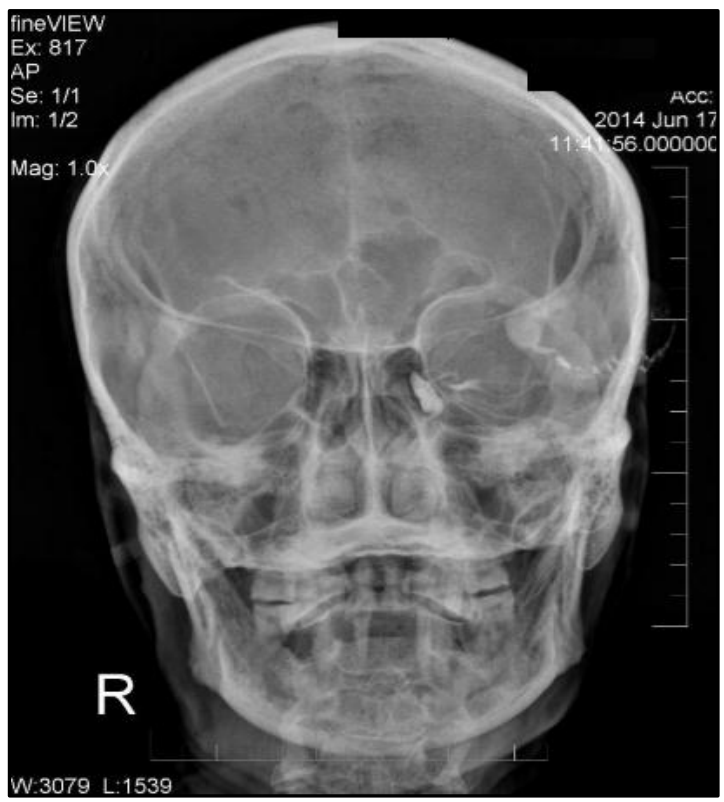

Fig. 2: Dacryocystogram done showing Fibrosed Sac 


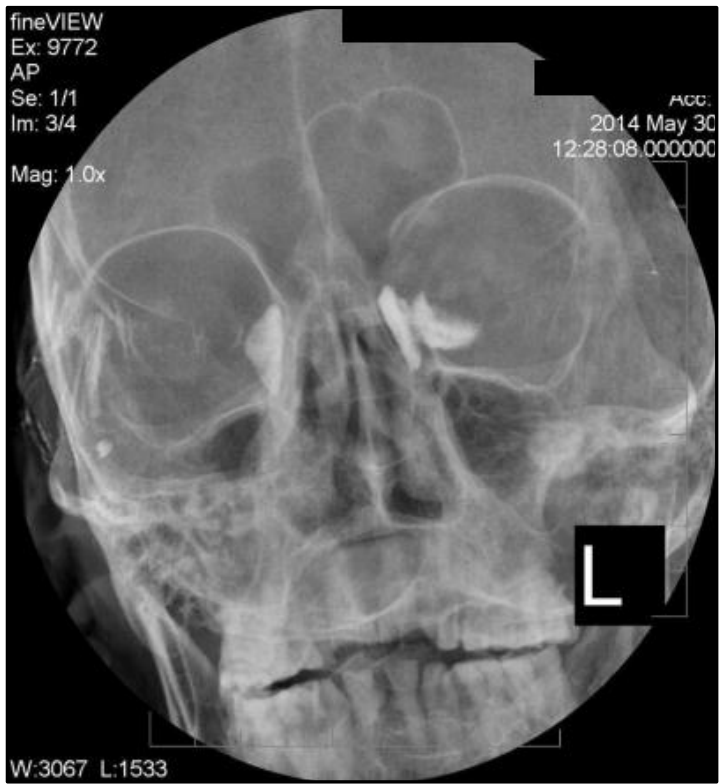

Fig. 3: Dacryocystogram done after DCT showing Residual Sac LE

\section{OBSERVATIONS}

Incidence of chronic dacryocystitis is found to be more common among females in the ratio of 1:3.4 showing female preponderance, attributed to narrow lumen in females. The older females and younger males were affected. The involvement of left side was more common than right side.

\begin{tabular}{|c|c|c|}
\hline Surgery & No. of Patients & Percentage \\
\hline DCT & 21 & $52.5 \%$ \\
\hline DCR & 16 & $40 \%$ \\
\hline DCT with Fistulectomy & 2 & $5 \%$ \\
\hline RE Exploration of SAC & 1 & $2.5 \%$ \\
\hline Total & 40 & $100 \%$ \\
\hline \multicolumn{3}{|c|}{$\begin{array}{c}\text { Table 1: Showing Surgical Decision } \\
\text { Based on Dacryocystogram }\end{array}$} \\
\hline
\end{tabular}

NLD block 95\% was more common than canaliculi block. Incomplete block was seen in $25 \%$ patients. The morphology of nasolacrimal sac was normal in 12 patients, distended in 17 patients and fibrosed (Fig. 2) in 11 patients. Dacryocystogram delineate the altered tract (Fistula) being external in 2 patients. Residual lacrimal sac (Fig. 3) following incomplete excision of sac was seen in one patient for whom DCT was performed earlier. Dacryolithiasis was also detected.

Analysis of the above data was done using epidemiological information package 17, using this software, frequencies, mean, percentages, Standard Deviations and ' $\mathrm{p}$ ' value were calculated. For qualitative variables Yate's test was used. A ' $p$ ' value less than 0.05 is being taken as a significant relationship.

\begin{tabular}{|c|c|c|}
\hline Outcome-Syringing & No. of Patients & Percentage \\
\hline $\begin{array}{l}\text { No regurgitation of } \\
\text { Mucopurulent Fluid }\end{array}$ & 28 & $70 \%$ \\
\hline $\begin{array}{l}\text { Regurgitation of Clear Fluid } \\
\text { through same Punctum }\end{array}$ & 7 & $17.5 \%$ \\
\hline $\begin{array}{l}\text { Regurgitation of Clear Fluid } \\
\text { through Opposite Punctum }\end{array}$ & 5 & $12.5 \%$ \\
\hline Total & 40 & $100 \%$ \\
\hline \multicolumn{3}{|c|}{ Table 2: Showing Follow-Up \& Outcome } \\
\hline
\end{tabular}

Based on Dacryocystogram finding, DCT was advised in maximum number of cases $55 \%$ followed by DCR $40 \%$ and excision of fistulous tract along with Dacryocystectomy was performed in $5 \%$ of them (Table 1). Outcome after surgery on follow-up with syringing showed no regurgitation of mucopurulent fluid in majority of cases, "p" value $<0.001$ and hence significant (Table 2). Hence, it is evident from the findings derived from this study that Dacryocystogram is a safe investigating modality in hands of skilled ophthalmologist and radiologist.

\section{CONCLUSION}

Dacryocystogram is easy to perform, harmless and it provides good imaging quality at a much lower cost and radiation exposure is much lower than compared to CT scan. In our opinion, it can be performed safely presuming that every patient suffering from dacryocystitis has to undergo DCG after syringing. It aids us to localise the level of block, analyse the changes in morphology of sac and lacrimal duct, at times the aetiological factor for epiphora can be diagnosed based on it, enabling us to meticulously plan the treatment for chronic dacryocystitis in a much better fashion, thereby better outcome following surgery can be achieved without recurrence.

\section{REFERENCES}

1. Pornpanich K, Luemsamran $\mathrm{P}$, Leelaporn A, et al Microbiology of primary acquired nasolacrimal duct obstruction: simple epiphora, acute dacryocystitis, and chronic dacryocystitis. Clin Ophthalmol 2016; 10: 337-42.

2. Semes L, Melore GG. Dilation and diagnostic irrigation of the lacrimal drainage system. J Am Optom Assoc 1986; 57(7):518-25.

3. Cheung LM, Francis IC, Stapleton F, et al. Symptom assessment in patients with functional and primary acquired nasolacrimal duct obstruction before and after successful dacryocystorhinostomy surgery: a prospective study. Br J Ophthalmol 2007;91(12):1671-4.

4. Xian MY, Jiang YQ, Zhang ZS. Clinical diagnosis of lacrimal duct obstruction by digital subtraction dacryocystography. Hunan Yi Ke Da Xue Xue Bao 2001; 26(1):86-8. 